\title{
Research on the Upgrading Strategies of Huaiyuan Rattan-plaiting Industry
}

\author{
Lingyun Yang ${ }^{1, *}$ \\ ${ }^{1}$ Urban Vocational College of Sichuan, Chengdu, Sichuan, China \\ *Corresponding author. Email:396895327@qq.com
}

\begin{abstract}
Through the field investigations in the early stage, this paper analyzes the practitioners of Huaiyuan rattanplaiting industry and the design and production of rattan-plaiting products, and summarizes the problems existing in Huaiyuan rattan-plaiting industry. Also, the upgrading strategies of Huaiyuan rattan-plaiting industry are proposed.
\end{abstract}

Keywords: Huaiyuan rattan-plaiting, Industry, Upgrading, Strategies.

\section{INTRODUCTION}

Huaiyuan rattan-plaiting is a traditional craft that has been passed down for thousands of years in Huaiyuan Town, and it is an intangible cultural heritage of Sichuan Province [1]. The natural material, elegant color and curved shape of rattan are in line with the modern ecological nature and the life concept of returning to the original nature. With the development of modern society and economy, people's material and spiritual life are greatly enriched. People have higher requirements for the appearance, structure, function, quality and brand of rattan-plaiting products [2]. However, most of the rattan-plaiting utensils produced and sold in Huaiyuan Town have been difficult to meet the aesthetic and daily needs of modern people. Therefore, it is urgent to innovate existing rattanplaiting products. From the perspectives of the training of employees in the rattan-plaiting industry, innovation of rattan-plaiting products, and brand building of rattan-plaiting products, this paper provides ideas for the upgrading of the rattanplaiting industry in Huaiyuan Town.

*Fund: This paper is supported by the Modern Design and Cultural Research Center of Sichuan Key Research Base of Philosophy and Social Sciences - The Inheritance of Traditional Rattan-plaiting Technology in Huaiyuan and Product Innovation Research (Project Number: MD20E005).

\section{INVESTIGATION ON THE STATUS QUO OF HUAIYUAN RATTAN-PLAITING INDUSTRY}

\subsection{The Staff Structure of Huaiyuan Rattan-plaiting Industry Is Unreasonable and the Ability of the Staff Is Not High}

Through interviews and investigations, most of the employees in the rattan-plaiting enterprises in Huaiyuan Town are the elderly. Due to efficiency issues, there are few young people engaged in the rattan-plaiting industry, and there is a lack of successors. The professional degree of operation and management staff is relatively low, their education degree of is not high, and the structure of knowledge and ability of them is relatively single. The design and production of rattan-plaiting products and the management of the enterprises mainly rely on their own experience, and the model of master-apprentice is adopted. The production follows the traditional crafts for hand plaiting. The production is backward and the production capacity is low. They are weak in design innovation, technological means, and market-oriented operation of enterprises, and are reluctant to invest in design and equipment. Most enterprises have almost no talents for innovative design and brand planning of rattan-plaiting products. 


\subsection{Huaiyuan Rattan-plaiting Products Have Traditional Modeling, and Its Material, Structure and Function Are Single}

According to the investigation, it is found that most of Huaiyuan rattan-plaiting products basically imitate traditional shapes, the overall appearance is relatively old, the color is dull, and Huaiyuan rattan-plaiting products lack the characteristics of the times, which does not meet the aesthetics of modern people, especially the aesthetic and use requirements of the younger generation. Secondly, most of the rattan-plaiting products are made of simple materials, basically composed of rattan materials, and a small amount of fabrics will be added. Then, the structure of traditional rattanplaiting products is restricted by the properties of rattan materials and traditional craftsmanship, and most of them use non-detachable structures [3]. The rattan materials are mainly fixed by nails, which makes the shape of rattan-plaiting products not concise and beautiful. At the same time, due to the non-detachable structure, it is not conducive to modern logistics and transportation, and does not conform to the current development trend of ecommerce. Finally, the function of rattan-plaiting products is relatively single, and there is a few of product categories. Due to changes in modern lifestyles and residential environment, the functions of rattan-plaiting products have not kept pace with the times.

\subsection{Huaiyuan Rattan-plaiting Products Lack Brand Building}

There are dozens of rattan-plaiting enterprises in Huaiyuan Town, but they are not large in scale and strong, and there are few influential rattanplaiting enterprises. Therefore, the product homogeneity of Huaiyuan rattan-plaiting industry is serious, the product price is low, and the added value is low. It has low influence outside the province or abroad, and it has not formed brand benefits.

\section{THE UPGRADING STRATEGIES FOR HUAIYUAN RATTAN- PLAITING INDUSTRY}

\subsection{Vigorously Strengthening the Training of Various Practitioners in the Rattan- plaiting Industry}

\subsubsection{Strengthening School-enterprise Cooperation and Jointly Cultivating Compound Talents Who Do Well in Theory and Practice [4]}

With the cooperation and training of talents, universities and enterprises can give full play to their respective advantages. Colleges and universities have theoretical system that enterprises do not have, while enterprises have advantages such as practice base and project operation that colleges and universities do not have. Therefore, mutual cooperation and communication are conducive to the cultivation of inter-disciplinary talents.

Universities and enterprises established a training base for rattan-plaiting creative design talents, forming a rattan-plaiting talent database. At the same time, they established an incubation base of rattan-plaiting products in colleges and universities. Graduates majoring in specialty related to design used rattan-plaiting projects as their graduation design topics, leading junior students to participate in and continuously strengthening the talent reserve force in the rattan-plaiting industry.

\subsubsection{Rattan-plaiting Enterprises Provide Opportunities to Improve Practical Ability and Theoretical Knowledge}

On the one hand, college students who have just graduated from colleges and entered rattan-plaiting enterprises still need to improve their practical ability. They also need have the practice through actual projects, or the master will lead the apprentice to continuously improve the practical ability. On the other hand, the old employees who have worked in the company for many years and the inheritors of intangible cultural heritage (rattanplaiting) also need to constantly update their knowledge. In today's ever-changing society, knowledge and skills are updated very quickly. Therefore, for the old employees, it is extremely important to re-learn theoretical knowledge and apply technological means. 


\subsection{Adhering to the Innovative Design of Rattan-plaiting Products}

\subsubsection{Modeling Innovation}

Based on the classic image of traditional rattanplaiting products, combined with the needs of modern life, the form is redesigned, with new functional meanings. Modern people pursue a minimalist style for the appearance of the product, and the shape is fashionable and artistic. Therefore, to deconstruct the appearance of modern household products with the image of traditional rattan- plaiting products and then recombine them, it is important to note that in the process of decomposition and reorganization, simple duplication and application of traditional shapes should be avoided, and the cultural characteristics contained in the image of traditional rattan-plaiting products should be explored. The unique elements can be extracted from it, so that the image of traditional products can be continued in modern products. At the same time, traditional cultural marks are injected into modern products to enhance the cultural connotation of modern products ("Figure 1").

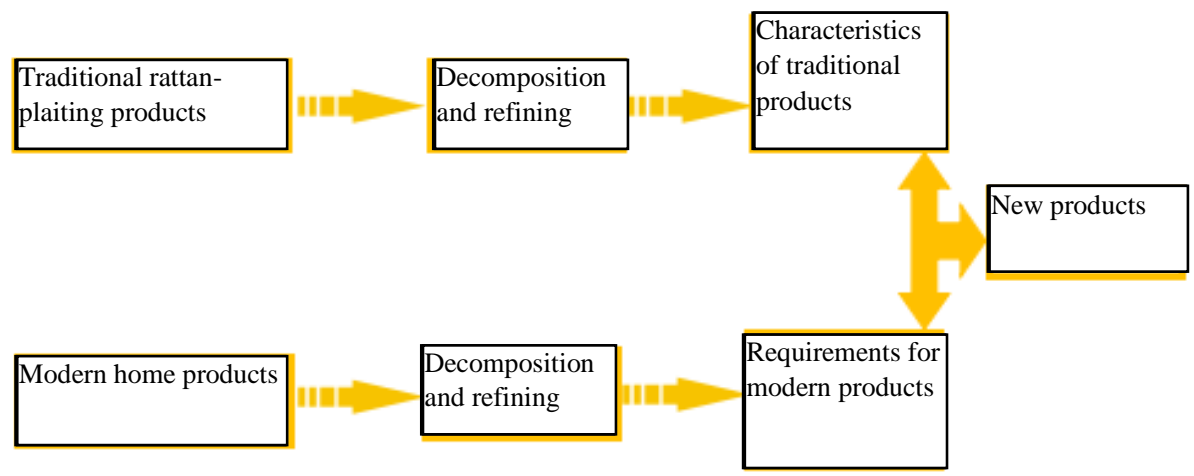

Figure 1 Concept decomposition and reorganization of rattan-plaiting products.

\subsubsection{Structure Innovation}

In order to achieve the innovation in structure, it is necessary to adopt modular design and detachable structure, that is, all rattan-plaiting products adopt the structure of "components + connectors". The components adopt modular design, with the standardization and generalization as the concepts. "One thing with multiple uses" is the main feature. Through modular design, multiple components can be combined in different ways to meet different usage requirements.

The modules are connected by standard connectors. Such structure design is simple and beautiful. The modules are connected by detachable connectors. The installation and disassembly are simple, and the logistics and transportation are convenient, which reduces the production cost of the enterprises and brings DIY for customers. More importantly, it adapts to the current Internet sales, which facilitates exporting abroad, and allows national products to go to the world.

\subsubsection{Material Innovation}

For a long time, the materials used in Huaiyuan rattan-plaiting products have been plaited with rattan silk and cane. Most of these rattans are used after stewing and drying. Although the rattans treated in this way have certain anti-corrosion properties, the lifespan is still limited, especially when it is applied outdoors or in humid places. In order to make the life cycle of rattan-plaiting products longer, the rattan material needs to be treated with anticorrosion, mildew and insect protection. In order to make rattan-plaiting products more fashionable and more artistic, the rattan can also be dyed.

The rattan has excellent flexibility, which is conducive to the modeling, but if all rattan-plaiting products are made of rattan, it will inevitably cause aesthetic fatigue. Therefore, the rattan and other materials can be combined, for instance, rattan + wood, rattan + metal, rattan + glass, rattan + plastic, etc. On the one hand, it increases the possibilities of rattan-plaiting products. On the other hand, the rattan is combined with other modern materials, forming a better contrast in terms of material and color. At the same time, it can also form 
complementary advantages with other materials, making rattan-plaiting products more perfect and more in line with the requirements of modern life.

\subsubsection{Process Innovation}

After thousands of years of inheritance, the techniques and decorative patterns of Huaiyuan rattan-plaiting products have been developed. In modern life, the decorative patterns of these traditional rattan-plaiting products are oldfashioned and monotonous, which are not suitable for modern people's aesthetics. Therefore, the bold innovation in traditional rattan-plaiting methods is also one of the important ways to promote the innovation of rattan-plaiting technology.

Using the current $2 \mathrm{D}$ and $3 \mathrm{D}$ technology to model and simulate the rattan-plaiting process can greatly increase the creative speed and increase creative solutions. According to different sizes, different shapes, and different colors of rattan on the computer, different plaiting technologies will be adopted, forming colorful rattan-plaiting patterns and textures and creating the desired style rattanplaiting products.

\subsection{Actively Building an Aircraft Carrier for the Rattan-plaiting Industry and Taking the Path of Brand Development}

It is required to cultivate a group of leading enterprises with strong comprehensive strength. First, it is to encourage existing enterprises to grow bigger and stronger, and attract capital investment in the rattan-plaiting industry. Second, it is necessary to guide rattan-plaiting enterprises to implement brand strategy. On the basis of improving product quality, it is suggested to further increase the popularity and market share of rattanplaiting products by means of registered trademarks, advertising and promotion, and building famous brands. Third, it is important to make the development at the province-level, the state-level, the international level. Also, it is necessary to actively expand markets outside the province and abroad, and adopt effective marketing and planning methods to expand product image.

\subsection{Improving the Policy Guarantee Mechanism for the Rattan-plaiting Industry}

\subsubsection{Improving the Intellectual Property Protection Law of the Rattan-plaiting Industry and Promoting the Healthy Development of the Rattan-plaiting Industry}

A good legal environment and standardized management system are important guarantees for the development of cultural and creative industries. At present, Huaiyuan rattan-plaiting industrial market is still in a low-level development stage, the industrial chain is not yet complete, the development scale of enterprise is small, and the legal system related to intellectual property rights is not yet sound. People's awareness of intellectual property protection is relatively weak [5], and imitating and plagiarizing the results of others' labor frequently occur. Therefore, relevant government departments should create a favorable development environment in which originality and intellectual property rights are respected through legislation, improved organization and laws and regulations on intellectual property rights protection.

\subsubsection{Strengthening the Government's Support to the Rattan-plaiting Industry and Building a Rattan-plaiting Enterprise}

The government should make policy preference to rattan-plaiting enterprises in taxation, financing, loan interest rates, etc. At the same time, under capable conditions, a special rattan-plaiting industrial park can be built, which is invested by the government and rattan-plaiting enterprises settled in, forming a large-scale industrial cluster effect. Also, the government will conduct make allrounded support for the potential and welldeveloped rattan-plaiting enterprises in industrial park, forming a group of star rattan-plaiting enterprises with certain influence in the country.

\section{CONCLUSION}

As the intangible cultural heritage of Sichuan Province, Huaiyuan rattan-plaiting has a long history of development. The development of Huaiyuan rattan-plaiting industry is not only to inherit the excellent traditional Chinese culture, but 
also to implement a new measure of the Party Central Committee and the State Council on the implementation of the rural revitalization strategy [6]. To this end, it is necessary to strengthen the training of talents in the rattan-plaiting industry, strengthen the innovation of rattan-plaiting products, improve the quality of products, enhance the brand benefits of rattan-plaiting products, perfect the guaranteeing policies of the rattanplaiting industry, and promote the sound and fast development of the rattan-plaiting industry in Huaiyuan.

\section{AUTHORS' CONTRIBUTIONS}

This paper is independently completed by Lingyun Yang.

\section{REFERENCES}

[1] Shu Bin. "Study on Rattan Furniture Innovation Design with "Huaiyuan Rattan" as an example" [D]. Southwest Jiaotong University, 2017. (in Chinese)

[2] Tian Yongpei. "A Brief Talk on the Application of Emotional Design Concepts in the Design of Home Products" [J]. Art and Literature for the Masses, 2017, 01, 15: 106. (in Chinese)

[3] Shu Bin. "Exploring the Modernization of Rattan Furniture Design" [J]. West Leather, 2019, 9, 25: 50-51. (in Chinese)

[4] Wang Rongrong. "The Necessity of SchoolEnterprise Cooperation in Secondary Vocational Education and Measures to Strengthen Cooperation" [J]. Reading Digest, 2016, 06:44. (in Chinese)

[5] Zheng Zhihai, Xue Rongjiu. "Accession to WTO and Intellectual Property Protection" [M]. China Foreign Economic Relations and Trade Press, 2000. (in Chinese)

[6] Shao Xiaoqin. An Analysis of the Implementation Strategy of the Inheritance and Development of Excellent Traditional Chinese Culture [J]. Literature, 2018. (in Chinese) 